\title{
Preface : Invited Issue Editor, Professor Joong-Uhn Choi, and the Era of Neuroendoscopy
}

\author{
Seung-Ki Kim, M.D., Ph.D., ${ }^{1,2}$ Kyu-Chang Wang, M.D., Ph.D.' \\ Editor of the 'Pediatric Issue,", JKNS; Chair, Publication Committee, ${ }^{2}$ KSPN
}

In 2015, the first Pediatric Issue of the Journal of Korean Neurosurgical Society was published. The Issue aims to share updated information on specific topics of pediatric neurosurgery with general neurosurgeons or those in other subspecialties. Because of the limited number of pediatric neurosurgeons in Korea, children with neurosurgical problems visit general neurosurgeons or those in other subspecialties at the first stage of treatment. The Pediatric Issue will be helpful not only for pediatric neurosurgeons but also for those who are not familiar with pediatric neurosurgical problems.

The topics of the first and the second Pediatric Issue in 2015 and 2016 were 'moyamoya disease' and 'craniosynostosis', and they were organized by invited Issue editors, Dr. Seung-Ki Kim, who was the chairperson of the Publication Committee of the Korean Society for Pediatric Neurosurgery (KSPN) and Dr. Joon-Ki Kang who is one of the former Presidents of International Society for Pediatric Neurosurgery (ISPN). The topic of the Pediatric Issue in 2017 is 'neuroendoscopy' and was organized by the invited Issue editor, Professor Joong-Uhn Choi who is another pioneer of pediatric neurosurgery in Korea (Fig. 1).

Professor Joong-Uhn Choi was born on May 17th, 1943 and graduated from Yonsei University College of Medicine in 1969. He was trained as a neurosurgical resident from 1970 to 1974 at Severance Hospital in Seoul and got the neurosurgical

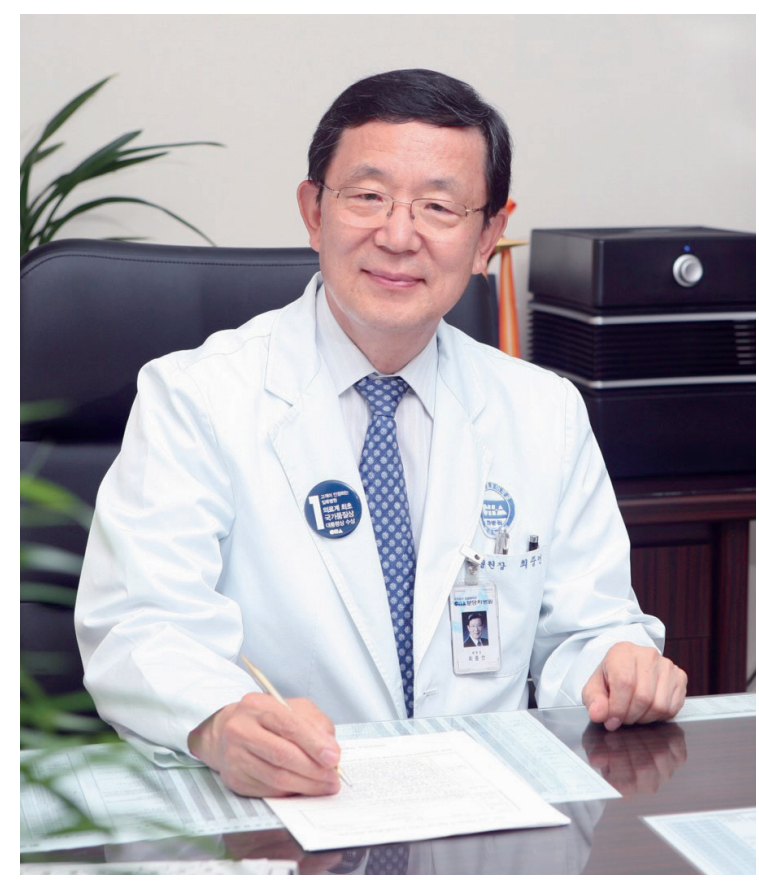

Fig. 1. Invited Issue Editor, Professor Joong-Uhn Choi.

- Received : January 5, 2017 •Revised : February 3, 2017 •Accepted : February 6, 2017

- Address for reprints : Kyu-Chang Wang, M.D., Ph.D.

Division of Pediatric Neurosurgery, Seoul National University Children's Hospital, Seoul National University College of Medicine, 101 Daehak-ro, Jongno-gu, Seoul 03080, Korea

Tel : +82-2-2072-3489, Fax : +82-2-2072-0274, E-mail : kcwang@snu.ac.kr

This is an Open Access article distributed under the terms of the Creative Commons Attribution Non-Commercial License (http://creativecommons.org/licenses/by-nc/4.0) which permits unrestricted non-commercial use, distribution, and reproduction in any medium, provided the original work is properly cited. 
board in 1974. After his military duty, he returned and joined the faculty of Department of Neurosurgery, Yonsei University College of Medicine and Severance Hospital where he worked until his retirement in 2008. Professor Choi has studied abroad as a clinical assistance and post-doctoral fellow at the Institute of Neurology, National Hospital in Queen Square, London from 1979 to 1980 under the guidance of Professors R. W. Gilliatt and L. Symon, and as a clinical fellow at the Division of Neurosurgery, Hospital for Sick Children in Toronto from 1984 to 1985 with the supervision of Professor H. J. Hoffman. After retirement from the Yonsei University, he went to the Cha Hospital Group and took the charges of important positions.

He had many roles in the field of science, education and administration for his college, hospital and academic societies including the Presidents of the Korean Neurosurgical Society (2004-2005) and ISPN (2005-2006). He was also involved in the foundation of KSPN with Professors Joon-Ki Kang, Byung-Kyu Cho and Hoon Kap Lee in 1987 and served as the President from 1992 to 1994 . He was particularly interested in the pediatric brain tumors, surgical treatment of spasticity and neuroendoscopy where he showed a great academic contribution. He is one of the pioneers of modern neuroendoscopy in Korea introducing endoscopic third ventriculostomy (ETV) and endoscopic fenestration of intracranial cysts. Moreover, he had extended the role of endoscopy to the management of intractable gelastic seizure which is caused by hypothalamic hamartoma: the endoscopic disconnection. His pertaining publications (Endoscopic disconnection for hypothalamic hamartoma with intractable seizure: report of four cases. J Neurosurg 2004; Treatment modality for intractable epilepsy in hypothalamic hamartomatous lesions. Neurosurgery 2008; Treatment modalities for intractable epilepsy in hypothalamic hamartoma. Adv Tech Stand Neurosurg 2012) are an important landmark of the academic advancement of KSPN.

Professor Choi was invited as the editor of Pediatric Issue of 2017: Neuroendoscopy, based on his great contribution to the field. During the last decade, remarkable advancements have occurred and the realm of neuroendoscopy was extended to the spine and skull base operations as well, owing to the refinement of surgical instruments including endoscopes, and sealing technology of skull defects preventing leakage of cerebrospinal fluid. Professor Choi wanted to share these advancements and trends with all members of Korean Neurosurgical Society.

Nine articles were contributed by leading researchers in this field in Korea, Japan and India. For the interpretation of outcome after ETV, Dr. Deopujari of India contributed an article to define the success or failure more clearly at the 'gray zone'. Dr. Nishiyama of Japan kindly joined us as an author to introduce the exoscopy to Korean colleagues in detail. Current and future perspectives are added at the end by Professor Choi.

We appreciate all of the contributors, especially those from India and Japan for their active participation as well as Professor Choi for his enthusiasm in the role as the invited editor. 